Please send trade news information and illustrations to Kate Craig at the BDJ, 64 Wimpole Street, London WIG 8YS.

For details see the 'How to use'

\section{Medical Sickness}

\section{announces research results}

Medical Sickness, specialist financial adviser to dentists and doctors, has announced the results of a research study about the careers and financial concerns of doctors and dentists.

Respondents to the survey, carried out in association with leading research agency NOP, included over 6,400 general medical practitioners, hospital consultants and general dental practitioners.

The research found that 63 per cent of take early retirement, 24 per cent of the under 30 age group plan a change of career and low morale is widespread amongst the professions, particularly as a result of recent changes.

052

\section{Direct from Southern Dental Industries}

Southern Dental Industries (SDI) amalgam capsule products Permite and Lojic+, which were distributed exclusively through Oral-B throughout the UK since 1982, are now being distributed by SDI.

Oral-B's distribution ceased on 9th October 2000 and SDI resumed responsibility for the distribution of Permite and section of the contents page. dentists over the age 45 are planning to

Reader response number:

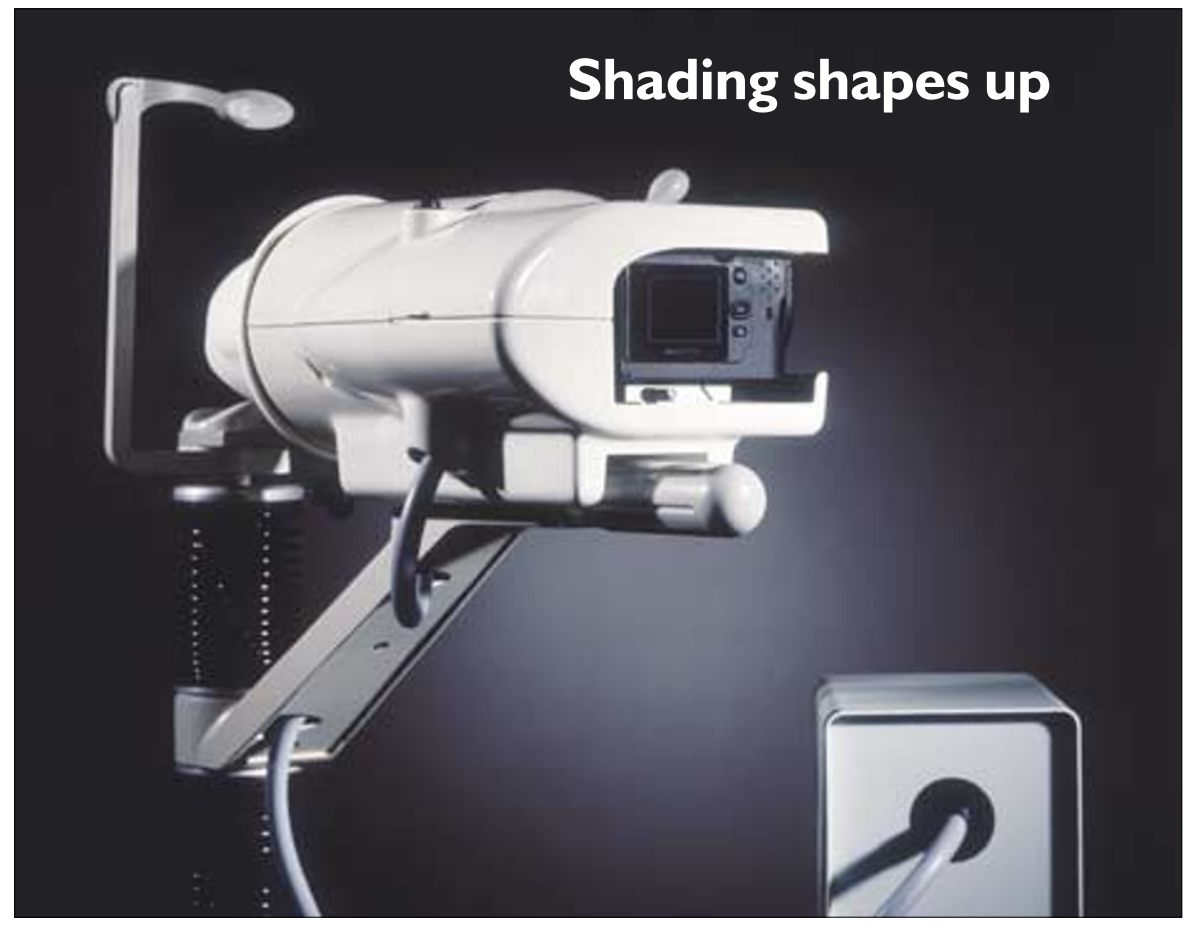

Ikam is a shade system designed to enhance communication between the GDP and the technician. Launching at the BDA conference, Ikam has been specifically developed in the UK by Metalor Technologies Ltd in conjunction with research company DentPark Ltd and Olympus Optical Europe to accurately analyse and communicate the shade, shape and contour of a natural tooth.

Ikam uses up-to-date technology to eliminate any potential inaccuracies, enabling laboratories to perform quality control checks.

Reader response number:

Lojic+ together with all SDI restoratives, including GS-80.

SDI is pleased to introduce the new Direct Placement Capsule System for Permite and Lojict.

This system eliminates the need for amalgam carriers and provides the dental profession with protection from the majority of mercury vapour as well as from cross-contamination for the patient.

Reader response number:

053

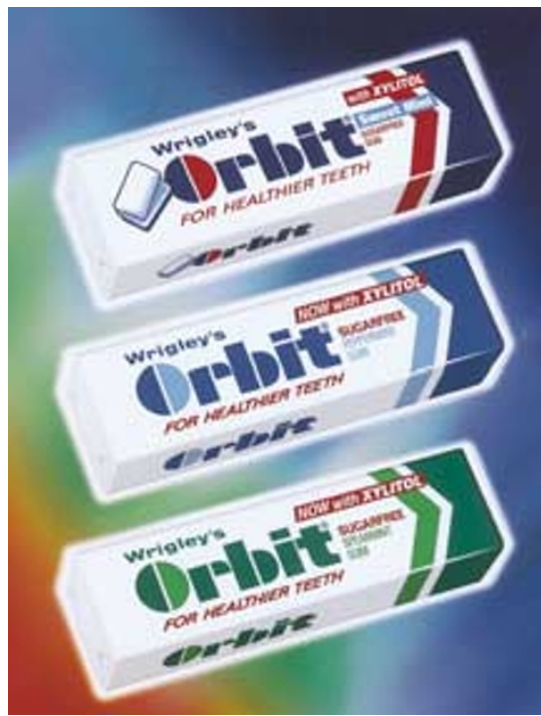

\section{In a new Orbit}

Orbit has been reformulated to contain xylitol, a natural sugar alcohol that has a clinically proven anti-caries effect.

In 1976 Orbit was the first sugarfree chewing gum to be launched in the UK, and Wrigley claims Orbit is now the fourth best selling sweet in the country. New reformulated Orbit comes in four different flavours and a choice of formats - spearmint, peppermint and lemon fresh in 5-stick packs and the new sweetmint 10 -pellet pack.

Orbit is available for dental practices to sell, as well as through retail outlets.

Reader response number:

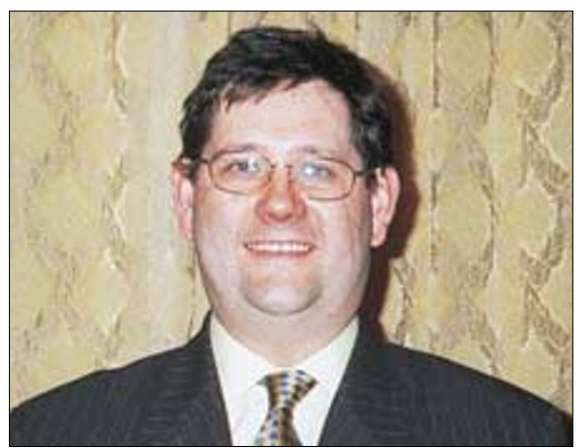

Managing director appointed

Frank Taylor and Associates, valuer and consultants, have announced that Chris Strevens has joined as managing director.

Chris Strevens, previously senior professions manager at Bank of Ireland, has joined Frank Taylor and Associates to broaden the range of services to include business coaching and an independent bank funding referral service.

For information on the range of services offered by Frank Taylor and Associates, including valuations, consultancy and financing, call 01707653260.

Reader response number: 